NBER WORKING PAPER SERIES

ON THE 'THEORY OF OPTIMAL TAXATION

IN A GROWING ECONOMY

Martin Feldstein

Working Paper No. 1435

\author{
NATIONAL BUREAU OF ECONOMIC RESEARCH \\ 1050 Massichusetts Avenue \\ Cambridge, MA 02138 \\ Augist 1984
}

The research reported here is part of the NBER's research program in Taxation and project in Government Budget. Any opinions expressed are those of the author and not those of the National Bureau of Economic Research. 
On the Theory of Optimal Taxation in a Growing Economy

\section{ABSTRACT}

This paper considers the following question: Would a "golden rule" capital accumulation policy of equating the marginal product of capital to the rate of growth of population be appropriate in a mixed economy in which the government does not have direct control over resource allocation but can use distortionary taxes to obtain resources for augmenting the private capital stock?

The key result derived here is that the golden rule level of capital intensity remains optimal. If the tax structure that prevails at the equilibrium does not alter the individual labor supply. This is true even if the constancy of labor supply represents a balancing of income effects and substitution effects of a distortionary tax. In contrast, if the form of the tax and the nature of the utility function imply that labor supply is distorted, the optimal capital intensity will in general not correspond to the golden rule level.

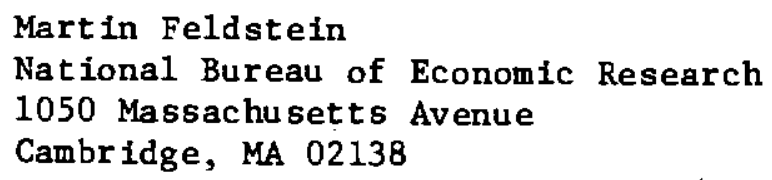

(617) $868-3905$ 


\title{
On the Theory of Optimal Taxation in a Growing Economy
}

\author{
Martin Feldstein*
}

In a centrally controlled economy, a government that wanted to maximize the steady state value of the utility of a representative individual would divide national resources between consumption and capital accumulation to equate the marginal product of capital to the rate of growth of population (Phelps, 1961). Would such a "golden rule" capital accumulation policy be appropriate in a mixed economy in which the government does not have direct control over resource allocation but can use taxes to obtain resources for augmenting the private capital stock? Surprisingly, this fundamental question in the theory of optimal taxation has not previously been addressed. ${ }^{1}$

The present paper shows that the golden rule of the centrally controlled economy may or may not be appropriate in a mixed economy and that whether it is or not depends on the behavior of labor supply and on the nature of the available tax. The key result is

\footnotetext{
*Harvard University and the National Bureau of Economic Research. I am grateful for discussions of this subject with John Fleming, Paul Krugman and Lawrence Lindsey.

${ }^{1}$ Diamond (1963) showed that government debt imposes a burden on future generations wherever the golden rule conditions does not hold but he did not go on to examine the question of optimal tax policy. Barro's (1979) discussions of optimal debt assumes explicitly that changes in government capital accumulation would be completely offset by induced changes in private capital accumulation; I shall ignore such induced intergenerational transfers in the present study. Atkinson and Sandmo (1980), King (1980) and others discuss how the optimal mix of consumption and income taxes depends on whether the economy is at the golden rule point but do not consider whether it is optimal to use a distortionary tax to achieve the golden rule level of capital intensity.
} 
that the golden rule level of capital intensity remains optimal if the tax structure that prevails at the equilibrium does not alter the individual labor supply. The paper demonstrates that this condition is satisfied for all individual utility functions if the government taxes only to affect aggregate capital intensity. More generally, however, if the government must raise tax revenue to finance government spending, the golden rule condition is not optimal unless either the labor supply is exogenously fixed or the combination of the tax structure and the utility function keeps the individually chosen labor supply unchanged.

The basic framework of this paper is an overlapping generations model of steady state growth. Individuals work in the first period of their lives and are retired in the second period. The government can levy a tax on their labor income and use the proceeds to augment private capital accumulation. 2 The individuals divide their after-tax earnings between first period consumption and saving for second period consumption, choosing in a way that maximizes their lifetime utility. The government's problem is to set a tax rate that maximizes steady state utility subject to the government's budget constraint, the capital accumulation relation, and the behavior implied by individual utility maximization.

Section 1 begins the paper with an analysis of the comrand economy. This provides a framework for describing the technical assumptions and derives the optimum conditions when the government has direct control over all resources. The second section then

2 This could take the form of either government investment or lending by the government to private firms. It is the opposite of government debt creation. 
examines a mixed economy with individual saving decisions but a fixed labor supply. In section 3 the assumption of a fixed labor supply is dropped and it is shown that the golden rule level of capital intensity remains optimal unless the tax structure is constrained to distort labor supply in equilibrium. The fourth section then abandons the assumption of a log-linear utility function that was used in sections 2 and 3 and derives the optimality of golden rule capital intensity without any restriction on the individual utility function. It is clear that this general result depends on the absence of any government spending. The fifth section therefore extends the analysis to an economy in which taxes must also finance government spending. In this context, golden rule capital intensity is optimal only if the taxes required to finance government spending would not alter the supply of labor.

1. The Command Economy

Consider an economy of identical individuals each of whom lives for two periods. At time $t$ there are $N_{t}$ young individuals ("workers") and $N_{t}(1+n)^{-1}$ older individuals ("retirees"), reflecting the fact that the population grows at rate n. Each worker supplies an amount of labor, $l$, and enjoys leisure $1-l$; retirees supply no labor. The total capital stock is $K$; the capital per unit of labor will be denoted $\mathrm{k}=\mathrm{K} / \mathrm{N}$.

Production is governed by a constant return to scale technology. Output per unit of labor is $f(k)$, output per worker is lf and the marginal product of capital is $f^{\prime}$.

In steady state growth the rate of increase of the capital stock must equal the rate of increase of the population: 
$\dot{\mathrm{K}} / \mathrm{K}=\mathrm{n}$. This implies that capital accumulation per worker, $\dot{\mathrm{K}} / \mathrm{N}=\mathrm{nK} / \mathrm{N}=\mathrm{nk} \ell$. The resources available for consumption by workers and retirees are equal to the difference between output per worker and capital accumulation per worker:

$$
c_{1}+\frac{c_{2}}{l+n}=\ell f-n k \ell
$$

where $c_{1}$ is the consumption per worker and $c_{2}$ is the consumption per retiree. The $1+n$ term reflects the fact that there are $1+n$ times as many workers as retirees.

If the utility of a representative individual is written $U\left(c_{1}, c_{2}, 1-\ell\right)$, the government's problem is to choose $c_{1}, c_{2}$ and $\ell$ to maximize this utility subject to the constraint of equation 1 . Alternatively, using that constraint to substitute for $c_{2}$ restates the government's problem as maximizing $U\left(c_{l},(l+n)\left(\ell f-n k l-c_{l}\right), l-\ell\right)$ with respect to $c_{l}, l$ and $k$. The first order condition with respect to $k$ is

$$
\mathrm{U}_{2 \ell} \ell(1+\mathrm{n})\left(\mathrm{f}^{\prime}-\mathrm{n}\right)=0 \text {, }
$$

which implies that capital accumulation should be extended until the golden rule intensity $\left(f^{\prime}=n\right)$ is achieved.

The derivative with respect to $c_{l}$ implies

$$
\mathrm{U}_{1}-(1+\mathrm{n}) \mathrm{U}_{2}=0 \text {, }
$$

indicating that the marginal rate of substitution between first and 
second period consumption should equal $1+n$. This is Samuelson's (1958) famous biological interest rate for optimal intertemporal allocation of consumption. When the marginal product of capital equals the population growth rate this is equivalent to equating the marginal rate of substitution to $1+f^{\prime}$.

The derivative with respect to the individual labor supply implies

(4) $(1+n)(f-n k) U_{2}-U_{3}=0$,

indicating that the marginal value of leisure most equal the increased utility of consumption that is possible when leisure is reduced by one unit. Note that this is not the increased output (f) but the increase in output minus the increased capital accumulation required to keep the capital per unit of labor unchanged ( $\mathrm{nk}$ ). This is multiplied by $1+n$ because, since the older generation is smaller by a factor of $1+n$, the amount available for consumption per retiree is greater by a factor of $1+n$.

Examining the special case of the log-linear utility function provides explicit solutions that are of interest in themselves and also useful for comparison with the results of sections 2 and 3 . If $\mathrm{u}=\alpha \ln \mathrm{c}_{1}+(1-\alpha) \ln \mathrm{c}_{2}+\beta \ln (1-\ell)$, or, equivalently, $\mathrm{u}=\alpha \ln \mathrm{c}_{1}$ $+(1-\alpha) \ln \left[\ell f-n k \ell-(1-n) c_{1}\right]+\beta \ln (1-\ell)$, we obtain directly that $\ell=$ $(1+\beta)^{-1}, c_{1}=\alpha(f-n k) /(1+n)(1+\beta)$ and $c_{2}=c_{1}(1-\alpha)(1+n) / \alpha$. The golden rule condition follows from the derivative of $u$ with respect to $k \operatorname{as}(l-\alpha)\left(f^{\prime}-n\right) l /\left(\ell f-n k l-(l+n) c_{1}\right)=0$. Note that, in taking this derivative, $c_{1}$ and $\ell$ can be taken as constants since the government sets them independently. 


\section{A Mixed Economy with Fixed Labor Supply}

In a mixed economy the government does not have direct control over individual consumption and labor supply but can only affect the allocation of resources through the tax system. I shall assume that the available tax is a linear tax on the labor income of workers. If the wage rate is $w$ per unit of labor, the tax collected per worker may be written $(1-\theta) w \ell+\tau$. Note that if $\tau>0, \tau$ is a lump-sum tax while if $\tau<0$, $\tau$ represents an exclusion of $-\tau /(1-\theta)$ and makes the tax progressive. Similarly, 1- $\theta$ is the marginal rate of tax and $\theta>1$ implies that the government subsidizes wages.

Each young individual works a fixed amount, $\ell$, and therefore has after-tax income of $\theta \mathrm{w} \ell-\tau$. If first period consumption is $c_{1}$, savings are $\theta w \ell-\tau-c_{1}$, and second period consumption is

$c_{2}=\left(\theta w \ell-\tau-c_{1}\right)\left(1+f^{\prime}\right)$

The total stock of privately-owned capital $\left(K_{p}\right)$ is equal to the savings done by the young of the previous generation:

(6) $\mathrm{K}_{\mathrm{p}}=\left(\theta \mathrm{w}_{\ell}-\tau-\mathrm{c}_{1}\right) \mathrm{N}(1+\mathrm{n})^{-1}$.

The growth of the capital stock is therefore

(7) $\dot{\mathrm{K}}_{\mathrm{p}}=\left(\theta \mathrm{w} \ell-\tau-\mathrm{c}_{1}\right) \mathrm{nN}(1+\mathrm{n})^{-1}$

since $\dot{\mathrm{N}}=\mathrm{nN}$. In steady state equilibrium, the privately-owned capital grows at the rate of population growth, $\dot{K}_{p} / K_{p}=n$ or, substituting into 7 and writing $\mathrm{k}_{\mathrm{p}}=\mathrm{K}_{\mathrm{p}} / \mathrm{N} \ell$

$$
\mathrm{n}=\frac{\left(\theta w \ell-\tau-\mathrm{c}_{1}\right) \mathrm{n}(1+\mathrm{n})^{-1}}{\ell \mathrm{k}_{\mathrm{p}}} .
$$

In steady state the private capital stock will have to be a constant fraction of the total capital stock. Denoting that fraction by 
$(1-\gamma)$ so that $k_{p}=(1-\gamma) k$, equation 8 can be rewritten as

(9) $(1-\gamma) k l=\left(\theta w \ell-\tau-c_{1}\right)(1+n)^{-1}$.

The growth of the government-owned capital stock $\left(\mathrm{K}_{\mathrm{g}}\right)$ is equal to the sum of the return on the existing government capital ( $\mathrm{K}^{f^{\prime}}$ ) and the tax collections $[(1-\theta) w \ell+\tau] N: 3$

(10) $\dot{\mathrm{K}}_{\mathrm{g}}=\mathrm{K}_{\mathrm{g}} \mathrm{f}^{\prime}+[(1-\theta) \mathrm{w} \ell+\tau] \mathrm{N}$.

since $\dot{\mathrm{K}}_{\mathrm{g}} / \mathrm{K}_{\mathrm{g}}=\mathrm{n}$ is a condition of steady state equilibrium, we obtain

(11) $\mathrm{n}=\mathrm{f}^{\prime}+[(1-\theta) w \ell+\tau] \frac{\mathrm{N}}{\mathrm{K}_{\mathrm{g}}}$,

or, writing $\mathrm{k}=\mathrm{K}_{\mathrm{g}} / \mathrm{N}$,

(12) $\left(n-f^{\prime}\right) \gamma k \ell=(1-\theta) w \ell+\tau$

Note that if $f^{\prime}>n$, a positive level of government-owned capital implies that taxes are negative or, alternatively, that taxes are needed only if there is a government debt, i.e., if $\mathrm{K}_{\mathrm{g}}<0$. This reflects the fact that the return on the government's capital (K $f^{\prime}$ ) exceeds the amount that is required to maintain a constant ratio of government capital per worker $\left(n \mathrm{n}_{\mathrm{g}}\right)$. Of course, with a positive level of government spending, the optimal level of taxes and government capital may both be positive.

Combining equations 9 and 12 eliminates the capital division constant $(\gamma)$ and defines the capital accumulation constraint:

(13) $-[(1-\theta) w \ell+\tau]=\left(f^{\prime}-n\right)\left[k \ell-\left(\theta w \ell-\tau_{1}-c_{1}\right)(1+n)^{-1}\right]$

The term in square brackets on the right hand side of the equation is the government capital stock per worker, that is, the

${ }^{3}$ I assume here that there is no government spending. 
difference between the equilibrium capital stock per worker and the private saving per worker. This government capital stock earns a return at rate $f^{\prime}$ but requires investment at rate $n$ to maintain itself. Thus the right hand side is the government's excess capital income. The left hand side is the value of those transfers expressed as negative tax revenue.

The individual selects $c_{l}$ to maximize utility or, using equation 5 ,

$$
u\left(c_{1}, c_{2}\right)=u\left[c_{1},\left(\theta w \ell-\tau-c_{1}\right)\left(1+f^{\prime}\right)\right]
$$

Knowing that $c_{l}$ will be selected in this way, the government selects $\theta$ to maximize this same utility function subject to the capital accumulation constraint of equation 13 . Stating the problem in this way implicitly takes $\tau$ as a fixed progressivity parameter of the tax system. Alternatively, $\theta$ and $\tau$ can be selected simultaneously subject to the capital accumulation constraint. With the supply of labor assumed constant, there is no difference between these two definitions of the problem since any combination of $\theta$ and $\tau$ that yields a given revenue has the same effect on economic activity.

To derive specific results requires an explicit parameterization of the utility function. The log-linear utility function adopted in the previous section implies that the individual chooses $c_{1}$ to maximize

$$
u=\alpha \ln c_{1}+(1-\alpha) \ln \left[\left(\theta w \ell-\tau-c_{1}\right)\left(1+f^{\prime}\right)\right]
$$


The individual's chosen value of $c_{l}$ is thus

$$
c_{1}=\alpha(\theta \omega \ell-\tau) \text {. }
$$

The government's problem is therefore to choose $\theta$ and $\tau$ to maximize

$$
\begin{aligned}
\mathrm{u} & =\alpha \ln [\alpha(\theta \mathrm{w} \ell-\tau)]+(1-\alpha) \ln [(1-\alpha)(\theta \mathrm{w} \ell-\tau)] \\
& +(1-\alpha) \ln \left(1+f^{\prime}\right) .
\end{aligned}
$$

or

$$
\mathrm{u}=\phi+\ln (\theta \mathrm{w} \ell-\tau)+(1-\alpha) \ln \left(1+f^{\prime}\right)
$$

where $\phi$ is a constant.

The maximization of $\mathrm{u}$ is subject to the capital accumulation constraint (equation 13) that establishes the link between the tax parameters and capital intensity and therefore between the tax parameter and $w$ and $f^{\prime}$ of equation 18. Equation 13 can be rewritten in the form

$$
\theta w \ell-\tau=\frac{w \ell+\left(f^{\prime}-n\right) k l}{1+\left(f^{\prime}-n\right)(1-\alpha)(1+n)^{-1}}
$$

The marginal productivity conditions imply that the wage rate per per unit of labor is $w=f-k f^{\prime}$. The numerator of equation 19 can therefore be rewritten as $\left(f-k f^{\prime}\right) \ell+\left(f^{\prime}-n\right) k l=(f-n k)$ and equation 19 becomes

$$
\theta w \ell-\tau=\frac{(f-n k)}{1+\left(f^{\prime}-n\right)(1-\alpha)(1+n)^{-1}}
$$

Note that, with fixed $\ell$, the expression $\theta w \ell-\tau$ is a function of $k$ only. What matters in the utility function of equation 18 is not the specific values of $\theta$ and $\tau$ but the combination $\theta w l-\tau$ and equation 20 establishes that this can be written as a function of $k$ only.

Substituting 20 into 18 gives the final form of the government's maximization: 
(21) $u=\phi+\ln \frac{(f-n k)}{1+\left(f^{\prime}-n\right)(1-\alpha)(1+n)^{-1}}+(1-\alpha) \ln \left(1+f^{\prime}\right)$.

Although the government does not control $k$ directly, the policy problem can be solved by obtaining the value of $k$ that maximizes equation 21 and then using 20 and the condition $w=f-k f$ to find values of $\theta$ and $\tau$ that are consistent with that value of $k$.

Setting the derivative of $u$ with respect to $k$ equal to zero yields:

$$
\frac{f^{\prime}-n}{(f-n k)}-\frac{(1-\alpha)(1+n)^{-1} f^{\prime \prime}}{1+\left(f^{\prime}-n\right)(1-\alpha)(1+n)^{-1}}+\frac{(1-\alpha) f^{\prime \prime}}{1+f^{\prime}}=0 .
$$

It is immediately clear that this is satisfied at $f^{\prime}=n$. This establishes that in this case the golden rule level of capital intensity remains appropriate even though the government does not have direct control over resources but can influence the capital accumulation process only by a tax on wage income.

Two implications of this result are of particular interest. Since $f^{\prime}=n$ at the optimum, it follows from equation 14 that the worker will allocate his net wage income between current consumption and future consumption until $u_{1}=(1+n) u_{2}$. This was the first order condition in the command economy for the optimal allocation of consumption between workers and retirees. Thus if the government establishes the correct macroeconomic level of capital intensity, the individuals will independently and automatically establish the correct allocation of income between present and future and therefore between young and old. 
The second implication of $\mathrm{f}^{\prime}=\mathrm{n}$ follows directly from equation 13. At the optimum, the government would collect no tax and make no transfers: $(1-\theta) w \ell+\tau=0$. The government's capital stock is then self-sustaining since the earnings on that capital are then just sufficient to finance the growth of the goverment's capital stock at rate $n: K_{g} f^{\prime}=n_{g}=\left(\dot{K}_{g} / K_{g}\right) K_{g}=\dot{K}_{g}$. This striking result should not be misunderstood. It should first be reiterated that in this economy there are no government services to be financed; the condition $(1-\theta) w \ell+\tau=0$ implies only that there should be no taxes to finance government capital accumulation and no distribution of the earnings of that capital. It should also be emphasized that this is only a condition of the steady state optimum. To reach this optimum, the government must accumulate its capital stock through a period of positive taxation. 4

\section{A Mixed Economy with Variable Labor Supply}

The analysis of the previous section will now be extended by assuming that both the government and the individual maximizes

$$
u=\alpha \ell n c_{1}+(1-\alpha) \ln c_{2}+\beta \ell n(1-\ell)
$$

As before $c_{2}=\left(\theta w l-\tau-c_{l}\right)\left(1+f^{\prime}\right)$. The individual's optimization problem again yields

${ }^{4}$ This assumes that, in the absence of government capital accumulation, the level of capital intensity would be less than the golden rule level. It is of course possible that the private equilibrium will involve excessive capital accumulation ( $f^{\prime}<n$ ) and that the optimal government cpaitla stock is negative, i.e., a government debt. But for plausible parameter values the private equilibrium will imply $f^{\prime}>n$. A sufficient but not necessary condition for this is that $k>f$ at the purely private equilibrium. 


$$
c_{1}=(1-\alpha)(\theta w l-\tau)
$$

and now also yields

$$
\ell=\frac{\theta w+\beta \tau}{(1+\beta) \theta w}
$$

Substituting these expressions into 23 and simplifying yields

$$
u=\phi+(1+\beta) \ln (\theta w \ell-\tau)+(1-\alpha) \ln \left(1+f^{\prime}\right)-\beta \ln \theta w .
$$

The government's problem is to maximize 26 subject to the capital accumulation constraint of equation 13 .

Note first that if the available tax is restricted to a proportional tax on labor income, i.e., if $\tau=0$, equation 26 reduces to equation 18 of the previous section. Since the capital accumulation constraint is unchanged, the optimum condition is again $f^{\prime}=n$. The crucial reason for this identical result with endogenous labor supply is found in equation 25. With $\tau=0, \ell=1 /(1+\beta)$ and is independent of the proportional tax rate $\theta$. Thus, in this case the variable labor supply is irrelevant and the individual always choose the optimal labor supply. ${ }^{5}$ of course, this insensitivity of the labor supply to a proportional tax is a property of the log-linear utility function.

In an alternative case in which the government is constrained to collect a lump sum tax $(\tau>0)$, or to make a lump sum transfer to everyone $(\tau<0)$, the first order condition for maximizing $u$

${ }^{5}$ Note that $\ell=1 /(1+\beta)$ is the optimum chosen in the command economy . 
in equation 26 with respect to $k$ does not yield $f^{\prime}=n$. If the tax system must distort the supply of labor, the golden rule is no longer an optimum condition.

A more general and more interesting constraint is to require that any tax revenue that is raised be raised in a particular non-proportional way, e.g., a progressivity requirement that sets the ratio of $-\tau$ to $(1-\theta)$ w. ${ }^{6}$ This case is interesting because, as noted in Section 2, when $f^{\prime}=n$ there is no need for any positive or negative tax revenue; the income that the government earns on its capital is just sufficient to finance the required steady state accumulation of government capital. But if no tax revenue or transfer is needed, the tax parameter values $\tau=(1-\theta)=0$ does not violate any progressivity requirement. So reaching a steady state equilibrium with the first best allocation of resources is not inconsistent with a requirement that any tax must be collected (or transfer made) in a progressive way.

4. Generalizing the Results

Although the specific results derived in Sections 2 and 3 reflected the assumption of a log-linear utility function and a linear wage tax, the analysis suggests that the basic conclusions can be extended to a more general specification of the problem. It is clear from the derivation of equation 13 that this capital accumulation constraint can be written more generally as

(27) $-T=\left(f^{\prime}-n\right)\left[k \ell-\left(w \ell-T-c_{1}\right)(1+n)^{-1}\right]$

${ }^{6}$ Progressivity as such is of no interest if all individuals are identical, but the current analysis can be extended directly to the case in which there is a distribution of wage rates. 
where $T$ is the tax collected from the workers and can be any function of $w, \ell$ and $c_{1}$. The significant feature of equation 27 is that at the golden rule level of capital intensity $T$ is zero. Thus, if the government can follow a tax and accumulation policy that eventually leads to a capital intensity at which $f^{\prime}=n$, it is no longer necessary to levy any tax. The reason for this is, as noted is section 2, that at $f^{\prime}=n$ the earnings of the government's capital stock are just enough to finance its steady state rate of growth. With $T=0$ and $f^{\prime}=n$, the worker's problem is to maximize

$$
u=u\left[c_{1},\left(w \ell-c_{1}\right)(1+n), 1-\ell\right]
$$

This has exactly the same first order conditions with respect to $c_{1}$ as in the command economy: $u_{1}=u_{2}(1+n)$. The first order condition with respect to $\&$ is $u_{3}=(1+n) w_{2}$. Substituting $w=f-k f$ for $w$ and rewriting this as $w=f-n k$, we obtain $u_{3}=(1+n)\left(f^{\prime}-n k\right) u_{2}$, the sare first order condition as equation 4 in the command econory.

Thus since no capital accumulation tax need actually be collected at the optimum, any tax system that can move the capital stock over time to the golden rule level of capital intensity can thereby achieve a first-best optimum for the economy with any utility function.

5. Government spending and Optimal Capital Intensity of course, taxes may also be needed in equilbrium to finance government outlays. If such taxes alter the supply of labor, it will not generally be optimal to achieve a golden rule level of capital intensity. But if the supply of labor is exogenously fixed 
(as in Section 2) or if the utility function and the tax structure imply that individuals choose an unchanging level of labor supply, the optimality of the golden rule capital intensity may persist.

Consider first the case of fixed labor supply and a log-linear utility function. If government spending does not enter the individual utility function or enters in an additively separable way, the individual's first order conditions will remain unchanged and the government's problem will, as in equation 18 , be to maximize

(29) $\mathrm{u}=\phi+\ln (\theta \mathrm{w} \ell-\tau)+(1-\alpha) \ln \left(1+f^{\prime}\right)$.

The need to finance government spending of $g$ per worker changes the government's capital stock accumulation equation to

$$
\dot{K}_{g}=K_{g} f^{\prime}+[(1-\theta) w \ell+\tau-g] N
$$

or, in steady state equilibrium,

(3l) $\left(n-f^{\prime}\right) y k \ell=(1-\theta) w \ell+\tau-g$.

The private capital accumulation condition remains unchanged in the form of equation 9. Combining that condition with equation 31 implies the overall capital accumulation condition

$$
g=\left(f^{\prime}-n\right)\left[k \ell-\left(\theta w \ell-\tau-c_{1}\right)(1+n)^{-1}\right]+[(1-\theta) w \ell+\tau]
$$

The first right hand side term in square brackets is the government's equilibrium capital stock per worker, i.e., the 
difference between the equilibrium capital stock per worker and the equilibrium private capital per worker. Multiplying this by $f^{\prime}-n$ gives the government's capital income in excess of the amount that it needs to maintain the capital stock. The second right hand side term is square brackets in the government's tax revenue per worker. Thus the right hand side gives the government's total net receipts per worker that finances the government spending of $g$ per worker. For $g>0$, we can now have $f^{\prime}>n$ and positive tax revenue.

Equation 32 can be solved to yield

$$
\theta w \ell-\tau=\frac{\ell(f-n k)-g}{1+(1-\alpha)\left(f^{\prime}-n\right)(1+n)^{-1}}
$$

using also $w=f-k f$ ' and $c_{I}=\alpha(\theta w l-\tau)$. Substituting this expression into 29 gives the government's maximand:

(34) $u=\phi+\ln \left[\frac{(f-n k)-g}{1+(1-\alpha)\left(f^{\prime}-n\right)(1+n)-1}\right]+(1-\alpha) \ln \left(1+f^{\prime}\right)$.

The derivative of $u$ with respect to $k$ gives the first order condition

$$
\frac{l\left(f^{\prime}-n\right)}{\ell(f-n k)-g}-\frac{(1-\alpha)(1+n)^{-1} f^{\prime \prime}}{1+(1-\alpha)\left(f^{\prime}-n\right)(1+n)^{-1}}+\frac{(1-\alpha) f^{\prime \prime}}{1+f^{\prime}}=0
$$

This is satisfied for $f^{\prime}=n$, showing that, with a fixed labor supply, the introduction of government spending has no effect or optimal capital intensity. 
Two features of this result deserve comment. First, although the conclusion was derived for a linear wage tax, the same analysis carries through for any tax that is a function of the wage income. Second, it follows directly from equation 32 that, with $f^{\prime}=n$, government spending and taxes are equal. Any permanent increase in government spending should therefore be financed by an equal increase in taxes.

Section 3 showed that, in the more general case of a variable labor supply, the golden rule level of capital intensity will remain optimal if the tax does not alter the supply of labor. This optimality property persists if the tax is used to finance government outlays. Introducing government outlays alters the capital accumulation constraint but not the individual's optimization problem. As before (equation 26), the government's maximand can be written

(36) $\mathrm{u}=\phi+(1+\beta) \ln (\theta \mathrm{w} \ell-\tau)+(1-\alpha) \ln \left(1+f^{\prime}\right)-\beta \ln \theta w$.

If the tax is proportional (so that $\tau=0$ ), the individual's optimization implies $\ell=1 /(1+\beta)$ and 36 can be rewritten as

(37) $u=\phi+\ln \theta w+(1-\alpha) \ln \left(1+f^{\prime}\right)$.

In place of equation 33, the capital accumulation constraint implies

$$
\theta w=\left[\frac{f-n k-g(1+\beta)}{1+(1-\alpha)\left(f^{\prime}-n\right)(1+n)^{-1}}\right]
$$


Substituting this into 37 gives

$$
u=\phi+\ln \left[\frac{f-n k-g(1+\beta)}{1+(1-\alpha)\left(f^{\prime}-n\right)(1+n)-1}\right]+(1-\alpha) \ln \left(1+f^{\prime}\right) .
$$

A comparison of equations 39 and 34 shows immediately that the first order condition will again be $f^{\prime}=n$. Thus, even with a variable labor supply and a positive amount of government spending to be financed, optimal government policy requires establishing the golden rule level of capital intensity if the available tax does not alter the actual supply of labor.

The significance of this result follows from the empirical finding that the uncompensated labor supply elasticity is quite small $1^{7}$ and therefore that a proportional tax has little effect on labor supply. 8 If this is a valid approximation, it indicates that the implications of the fixed labor supply case remain relevant in considering the implications of optimal taxation and capital accumulation.

August 1983

${ }^{7}$ See the evidence summarized in Atkinson and Stiglitz (1980), Chapter 2. Rosen (1976) shows that the labor supply elasticity of married women is substantially greater than that of married men.

${ }^{8}$ Hausman's (1981) analysis shows that the actual progressive income tax has significant labor supply effects even though a proportional tax would not. 
Atkinson, A.B. and Sandmo, Agnes (1980), "Wel fare Implication of the Taxation of Savings," Economic Journal,90, pp. 529-549.

Atkinson, A.B. and Stiglitz, Joseph E. (1980) Lectures on Public Economics, New York: McGraw Hill, Inc.

Barro, R. (1979), "On the Determination of the Public Debt," Journal of Political Economy, 87, 5, 940-971.

Diamond, P.A. (1965), "National Debt in a Neoclassical Growth Model," American Economic Review, 55, 1125-1150.

Hausman, J. (1981), "Labor Supply" in How Taxes Affect Economic Behavior, H.J. Aaron and J.A. Pechman, eds, Washington, D.C.: The Brookings Institution, 27-83.

King, M.A. (1980), "Savings and Taxation," Essays in Public Policy, G.A. Hughes and G.M. Heal, eds, London, Chapman and Hall.

Phelps, E.S. (1961), "The Golden Rule of Accumulation: A Fable," American Economic Review, 51, 638-43.

Rosen, H.S. (1976), "Taxes in a Labor Supply Model with Joint Wage-Hours Determination, Econometrica, 44, 485-507.

Samuelson, P.A. (1958), "An Exact Consumption-Loan Model of Interest With or Without the Social Contrivance of Money," Journal of Political Economy, 66, 467-482. 